\title{
Comparison of the recruitment of transverse abdominis through drawing-in and bracing in different core stability training positions
}

\author{
Navid Moghadam', Maryam Selk Ghaffari', Pardis Noormohammadpour ${ }^{1,2}$, Mohsen Rostami ${ }^{3,4},{ }^{4}$ Mohammad Zarel ${ }^{5}$, Mersad Moosavi ${ }^{5}$, \\ Ramin Kordi ${ }^{1, *}$
}

${ }^{1}$ Sports Medicine Research Center, Neuroscience Institute, Tehran University of Medical Sciences, Tehran, Iran ${ }^{2}$ Department of Sports and Exercise Medicine, School of Medicine, Tehran University of Medical Sciences, Tehran, Iran

${ }^{3}$ Brain and Spinal Cord Injuries Research Center, Neuroscience Institute, Tehran University of Medical Sciences, Tehran, Iran

${ }^{4}$ Department of Neurosurgery, Shariati Hospital, Tehran University of Medical Sciences, Tehran, Iran

${ }^{5}$ Department of Orthopedics, Tehran University of Medical Sciences, Tehran, Iran

There are many proposed core stability exercises in a variety of positions; however, it is not clear that in which position, activation of transverse abdominis muscle is utmost. We aimed to compare the activation of transverse abdominis muscle in different core stability exercise positions through ultrasound imaging. in a 20 subjects' study we compared the effectiveness of drawing-in and bracing maneuvers on transverse abdominis in different core stability exercise positions (supine, hook lying, supine with $90^{\circ}$ flexed knee and hip, supine with stretched knees and $90^{\circ}$ flexed hips, bridge, bridge with one stretched knee and Bird dog). We used activation ratio and preferential activation ratio as measurements of transverse abdominis activation. Abdominal Bracing in the bridge position showed the highest activation of transverse abdominis $(P<0.05)$. The results showed significantly higher activation of transverse abdominis, measured by preferential activation ratio, in bridge position during abdominal bracing.

Keywords: Abdominal muscles, Low back pain, Rehabilitation

\section{INTRODUCTION}

Low back pain is the most prevalent musculoskeletal problem; its lifetime and point prevalence are $58 \%$ to $84 \%$ and $4 \%$ to $33 \%$ respectively (Woolf and Pfleger, 2003). The loss of lumbar spinal stability is considered as a risk factor of low back pain (Panjabi, 1992). Transversus abdominis ( $\operatorname{Tr} A)$, the deepest abdominal muscles, plays major role in stabilization of lumbopelvic region (Willson et al., 2005). Reduced activation of the $\operatorname{Tr} A$ has been linked to the incidence and progression of low back pain (Ferreira et al., 2004). On the basis of this, activation and strengthening of $\operatorname{Tr} A$ have been suggested as possible therapeutic interventions in patients with low back pain (Panjabi, 1992; Selkow et al., 2017). The efficacy of these treatments has been shown in previous studies
(Noormohammadpour et al., 2012; Noormohammadpour et al., 2018).

The rehabilitation approach toward low back pain usually includes core stability exercises to enhance the spinal stabilization (Hwangbo et al., 2015; Noormohammadpour et al., 2018). There are many proposed core stability exercises in variety of positions (supine, quadruped, etc.) Drawing-in and bracing are two principle maneuvers that are routinely used by conservative therapists for specific activation of abdominal muscles including $\operatorname{Tr} A$ (Maeo et al., 2013). However, it is not clear that in which position, activation of $\operatorname{Tr} A$ muscle through drawing-in and bracing maneuvers, is utmost.

An ultrasound (US) imaging study has been used as a technique for assessing $\operatorname{Tr} A$ activation by measuring muscle thickness in rest-
${ }^{\star}$ Corresponding author: Ramin Kordi (iD https://orcid.org/0000-0002-0116-3018 Sports and Exercise Medicine Research Center, School of Medicine, Tehran

University of Medical Sciences, Tehran 14395-578, Iran

E-mail: ramin_kordi@tums.ac.ir

Received: October 17, 2019 / Accepted: November 22, 2019
This is an Open Access article distributed under the terms of the Creative Commons Attribution Non-Commercial License (http://creativecommons.org/licenses/by-nc/4.0/) which permits unrestricted non-commercial use, distribution, and reproduction in any medium, provided the original work is properly cited. 
ing and contraction states (Djordjevic et al., 2014). The reliability and validity of US imaging studies have been reported previously (Ehsani et al., 2016; Rostami et al., 2015). The aim of this study is to investigate and compare the effectiveness of drawing-in and bracing maneuvers in different core stability exercise positions (including supine, hook lying, supine with $90^{\circ}$ flexed knees and hips, supine with stretched knees and $90^{\circ}$ flexed hips, bridge, bridge with one stretched knee and bird dog) through US imaging.

\section{MATERIALS AND METHODS}

We conducted a comparative cross-sectional study to examine the activation of $\operatorname{Tr} A$ in different core exercise positions.

\section{Participants}

We asked 20 healthy volunteers with the age of 18 to 50 years who were screened for medical and medication history that could adversely affect muscle health or contraindicate testing included in the study. Exclusion criteria included self-reported history of low back pain in past 6 months and any previous musculoskeletal disease. We also excluded subjects who had practiced core training within past 6 months. All subjects received written and oral information about the study procedures before participation. Also, the study protocol was approved by the Ethical Committee of university (IR.TUMS.VCR.REC.1397.698). With the purpose of preventing measurement bias, all the participants were instructed not to consume meals or liquids $3 \mathrm{hr}$ prior to measurement (Kordi et al., 2011; Noormohammadpour et al., 2015).

\section{Instrument}

One musculoskeletal ultrasonography practitioner performed the US measures. Our investigator used a portable M-Turbo US system (FUJIFILM SonoSite Inc., Bothell, WA, USA) with a 13$\mathrm{MHz}$ linear transducer to visualize and obtain an US image of lateral abdominal wall muscles including $\operatorname{Tr} A$ during different positions.

\section{Measurement positions}

We measured changes in muscle thickness of lateral abdominal wall muscles in resting condition and during both drawing-in and bracing in the following seven positions: supine, hook lying, supine with $90^{\circ}$ flexed knee and hip, supine with stretched knees and $90^{\circ}$ flexed hips, bridge, bridge with one stretched knee, and Bird dog. Fig. 1 shows the positions in which measurements were done. The participants performed a drawing-in maneuver by drawing the navel up and in toward the spine and maintaining the
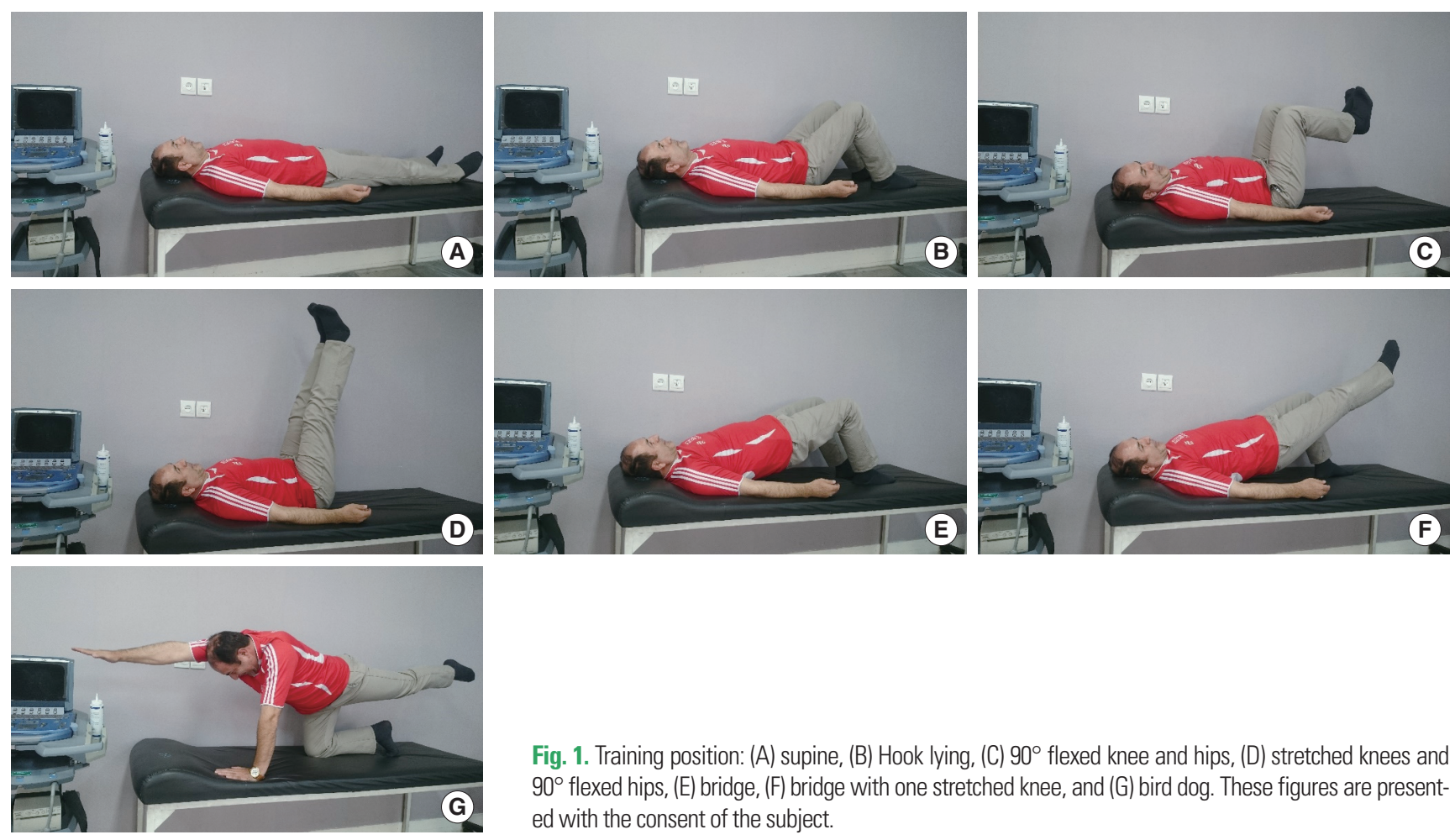

Fig. 1. Training position: (A) supine, (B) Hook lying, (C) $90^{\circ}$ flexed knee and hips, (D) stretched knees and $90^{\circ}$ flexed hips, (E) bridge, (F) bridge with one stretched knee, and (G) bird dog. These figures are presented with the consent of the subject. 
lumbar spine in a neutral position (Monfort-Pañego et al., 2009). The investigator also instructed participants to perform the bracing in maneuver by contracting the entire abdominal wall without any change in the position of the muscles and maintaining the lumbar spine in a neutral position (Monfort-Pañego et al., 2009).

\section{Measurements}

The transducer was being placed along the midaxillary, at the midway from the iliac crest and lower border of last rib. The transducer was adjusted to portray the best image quality, perpendicular to the skin surface. Two series of US images were obtained for each maneuver in each training position. We measured muscle thickness as the distance from the superior facial border to the inferior facial border of the muscle in millimeters after acquiring still B mode images. The investigator acquired images on the dominant side of each subject. In case of bird dog training position, the participants were instructed to use their nondominant side arm and dominant side leg. For US measurement at bridge position with the stretched knee, subjects were asked to stretch their nondominant side knee.

\section{Outcome measurements}

We used activation ratio (AR) and preferential activation ratio (PAR) of $\operatorname{Tr} A$ as final measurements of $\operatorname{Tr} A$ activation in drawingin and bracing maneuvers during different training positions. In this regard, AR was defined as maneuvered $\operatorname{Tr} A$ thickness divided by rest $\operatorname{Tr} A$ thickness and PAR was defined as a preferential increase in $\operatorname{Tr} A$ thickness by doing the maneuver in compare to total lateral abdominal wall change.

$$
\begin{gathered}
\mathrm{AR}=\left(\frac{\text { maneuvered } \operatorname{Tr} A}{\text { rest } \operatorname{Tr} A}\right) \\
\mathrm{PAR}=\frac{\left[\left(\frac{\text { maneuvered } \operatorname{Tr} A}{\text { maneuvered LatAbdWall }}\right)-\left(\frac{\text { rest } \operatorname{Tr} A}{\text { rest LatAbdWall }}\right)\right]}{\left(\frac{\text { rest TrA }}{\text { rest LatAbdWall }}\right)}
\end{gathered}
$$

The reliability of AR and PAR in the estimation of TrA thickness and their relevance with clinical outcomes have been shown

Table 1. Descriptive characteristics of study subjects

\begin{tabular}{lc}
\hline Characteristic & Value \\
\hline Age $(\mathrm{yr})$ & $29.50 \pm 3.34$ \\
Female gender & $18(90)$ \\
Height $(\mathrm{cm})$ & $165.75 \pm 4.95$ \\
Mass $(\mathrm{kg})$ & $58.45 \pm 9.52$ \\
Body mass index $\left(\mathrm{kg} / \mathrm{m}^{2}\right)$ & $21.20 \pm 2.66$ \\
\hline
\end{tabular}

Values are presented as mean \pm standard deviation or number (\%). in the previous study (McPherson and Watson, 2012; Mangum et al., 2016).

\section{Statistical analysis}

The normality of measured variables was assessed with ShapiroWilk test (Mishra et al., 2019). We have used paired sample t-test to compare the difference between activation measurements of drawing-in and bracing maneuvers in each core training position. To compare the results between different positions, analysis of variance (ANOVA) with repeated measures was used. All statistical analyses were conducted using IBM SPSS Statistics ver. 22.0 (IBM Co., Armonk, NY, USA).

\section{RESULTS}

In total, 25 subjects were invited but five participants were excluded before ultrasonography due to low back pain in last month $(\mathrm{n}=2)$, kyphosis $(\mathrm{n}=1)$ and practice of core training in the past 6 months $(n=2)$. Finally, 20 participants completed the ultrasonography in all positions. Table 1 shows the demographic findings of subjects including age, gender, height, weight, and body mass index.

Table 2 presents measurements of $\operatorname{Tr} A$ thickness during rest, abdominal drawing-in $(\mathrm{AD})$ and abdominal bracing $(\mathrm{AB})$ in different training positions. Table 3 reports the results of repeated measure ANOVA tests to compare the activation of $\operatorname{Tr} \mathrm{A}$ in differ-

Table 2. The thickness of TrA during rest, abdominal drawing-in, and abdominal bracing in different training positions

\begin{tabular}{lccc}
\hline Position & Rest & Maneuver & P-value \\
\hline Supine & $0.30 \pm 0.07$ & AD: $0.44 \pm 0.11$ & $<0.01^{*}$ \\
& & AB: $0.52 \pm 0.11$ & \\
Hook lying & $0.31 \pm 0.05$ & AD: $0.43 \pm 0.12$ & 0.07 \\
& & AB: $0.48 \pm 0.08$ & \\
90 flexed knee and hip & $0.31 \pm 0.09$ & AD: $0.42 \pm 0.13$ & $<0.01^{*}$ \\
& & AB: $0.54 \pm 0.13$ & \\
Stretched knees and $90^{\circ}$ flexed hips & $0.33 \pm 0.06$ & AD: $0.48 \pm 0.15$ & 0.28 \\
& & AB: $0.51 \pm 0.13$ & \\
Bridge & $0.40 \pm 0.20$ & AD: $0.54 \pm 0.17$ & $<0.01^{*}$ \\
& & AB: $0.60 \pm 0.16$ & \\
Bridge with one stretched knee & $0.36 \pm 0.18$ & AD: $0.50 \pm 0.18$ & 0.38 \\
Bird Dog & & AB: $0.52 \pm 0.17$ & \\
& $0.40 \pm 0.14$ & AD: $0.43 \pm 0.12$ & $<0.01^{*}$ \\
& & AB: $0.53 \pm 0.16$ & \\
\hline
\end{tabular}

Values are presented as mean \pm standard deviation $(\mathrm{cm})$ or number $(\%)$. TrA, transverse abdominis; $A D$, abdominal drawing-in; $A B$, abdominal bracing. ${ }^{*} P<0.05$, paired $t$-test between TrA thickness in $A D$ and $A B$. 
Table 3. Activation measures of TrA in different core training positions

\begin{tabular}{|c|c|c|c|c|c|c|c|c|c|}
\hline \multirow[b]{2}{*}{ Maneuver } & \multirow[b]{2}{*}{ Measure } & \multicolumn{7}{|c|}{ Positions } & \multirow[b]{2}{*}{$P$-value } \\
\hline & & Supine & Hook lying & $\begin{array}{l}90^{\circ} \text { flexed knee } \\
\text { and hip }\end{array}$ & $\begin{array}{l}\text { Stretched knees and } \\
90^{\circ} \text { flexed hips }\end{array}$ & Bridge & $\begin{array}{l}\text { Bridge with one } \\
\text { stretched knee }\end{array}$ & Bird dog & \\
\hline \multirow[t]{2}{*}{$A D$} & $A R$ & $1.52 \pm 0.46$ & $1.47 \pm 0.45$ & $1.45 \pm 0.51$ & $1.65 \pm 0.56$ & $1.85 \pm 0.60$ & $1.70 \pm 0.51$ & $1.54 \pm 0.59$ & $0.02 *$ \\
\hline & PAR & $0.27 \pm 0.38$ & $0.26 \pm 0.35$ & $0.07 \pm 0.42$ & $0.15 \pm 0.37$ & $0.43 \pm 0.46$ & $0.37 \pm 0.50$ & $0.29 \pm 0.49$ & $<0.01^{*}$ \\
\hline \multirow[t]{2}{*}{$A B$} & $A R$ & $1.76 \pm 0.29$ & $1.68 \pm 0.43$ & $1.86 \pm 0.56$ & $1.78 \pm 0.53$ & $2.06 \pm 0.56$ & $1.74 \pm 0.49$ & $1.90 \pm 0.76$ & 0.10 \\
\hline & PAR & $0.36 \pm 0.23$ & $0.37 \pm 0.35$ & $0.25 \pm 0.43$ & $0.17 \pm 0.43$ & $0.49 \pm 0.49$ & $0.36 \pm 0.53$ & $0.45 \pm 0.54$ & $0.02^{*}$ \\
\hline
\end{tabular}

Values are presented as mean \pm standard deviation.

TrA, transverse abdominis; $A D$, abdominal drawing-in; $A B$, abdominal bracing; $A R$, activation ratio; PAR, preferential activation ratio.

${ }^{*} P<0.05$, repeated measure analysis of variance within subjects' effect of position.

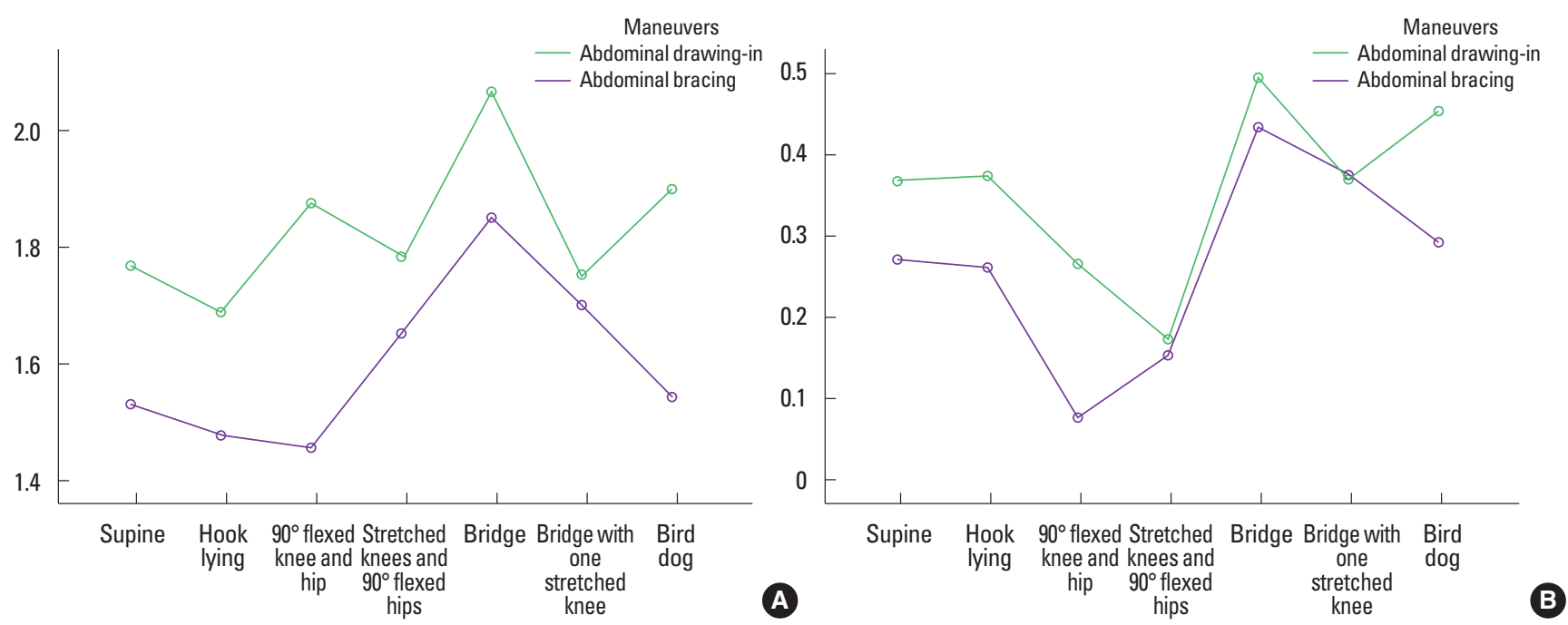

Fig. 2. Recruitment of transverse abdominis in each training position. (A) Activation ratio, (B) preferential activation ratio.

ent positions with $\mathrm{AD}$ and $\mathrm{AB} . \mathrm{AB}$ in the bridge position showed the highest activation of TrA. Fig. 2 also can be used to compare $A R$ and PAR of TrA in different positions.

\section{DISCUSSION}

One of the most important functions of abdominal muscles is to increase trunk stability (Heidari et al., 2015; Norris, 1993). Therefore, designing any abdominal muscle exercises, one should consider the stabilizing roles of these muscles. The present study investigated $\operatorname{Tr} A$ activation differences in drawing-in and bracing maneuvers in various core stability exercise positions through US imaging. The results show significantly higher activation of $\operatorname{Tr} A$, measured by PAR, in bridge position during AB. There has been substantial attention in the previous studies regarding the role of $\operatorname{Tr} A$ as the deepest abdominal muscles (Ehsani et al., 2016), and the approach to train this muscle (Hodges, 1999; Noormoham- madpour et al., 2012).

Patients with low back pain usually show a smaller increase in transverse abdominis thickness during their tasks. Similar results in EMG suggests impaired motor control of transverse abdominis among low back pain patients (Ekstrom et al., 2007). It has been indicated that the thickness of transverse abdominis muscle has correlation with its activity (Hodges and Moseley, 2003; McMeeken et al., 2004). That's why $\operatorname{Tr} A$ is one of the main targets of exercises aimed to prevent and rehabilitate low back pain. Drawing-in maneuver or $\mathrm{AD}$ aims to activate $\operatorname{Tr} \mathrm{A}$ while minimizing the contraction of other abdominal wall muscles such as the oblique muscles (Hodges, 1999). AB, on the other hand, has been suggested to activate the entire abdominal wall (Grenier and McGill, 2007). In this study, $\mathrm{AB}$ produced more $\mathrm{Tr} A$ activity comparing to $\mathrm{AD}$ maneuver. Both AR and PAR of $\operatorname{Tr} A$ were significantly higher during the $\mathrm{AB}$ maneuver. There is limited evidence comparing $\mathrm{AB}$ and drawing-in maneuvers in terms of $\operatorname{Tr} A$ activation. In a recent study, 
these two techniques were compared in 20 young healthy male subjects while they were lying supine with their knee flexed (Kim and Lee, 2017) and EMG showed significantly more $\operatorname{Tr} A$ activity during $\mathrm{AD}$ comparing to $\mathrm{AB}$. One possible explanation for the different results could be the way subjects were instructed to perform $\mathrm{AD}$ in which in contrast to our study they were not asked to maintain their neutral spine position while performing the maneuver (Kim and Lee, 2017). In another study conducted by Kim et al. (2016), US was employed to measure muscle activation and thickness. In their study, $\operatorname{Tr} A$ change ratio ( $\operatorname{Tr} A$ contract $-\operatorname{Tr} A$ rest $) /(\operatorname{Tr} A$ rest $\times 100)$ was calculated and compared between drawing-in and bracing. In terms of change ratio, drawing-in was greater than bracing. Additionally, all measures in Kim's study were taken in the standing position, a position that was not assessed in our study. Computed tomography findings also show $\mathrm{AD}$ to be more effective in producing $\operatorname{Tr} A$ contractions (Koh et al., 2014). Although some studies show better $\operatorname{Tr} A$ activity during $A D$, our finding suggests otherwise. Measuring TrA elasticity using US it has also been documented that $\mathrm{AB}$ produces higher $\operatorname{Tr} \mathrm{A}$ elasticity comparing to six other training strategies including $\mathrm{AD}$ (Hirayama et al., 2017). The difference in the methods measuring $\operatorname{Tr} A$ activity and subjects' positions could be an explanation for these discrepancies.

The AR formula, calculated by dividing thickness in the contracted state by thickness at rest, is a measure of activation for $\operatorname{Tr} A$ (Teyhen et al., 2005; Mangum et al., 2016). This measure helps clinicians determine the ability to activate the $\operatorname{Tr} A$. However, by taking into account only at rest and contracted states of $\operatorname{Tr} A$, this calculation cannot determine the ability to activate $\operatorname{Tr} A$ alone without evoking a contraction of other abdominal wall muscles. Most rehabilitation programs focus on teaching the patients to contract $\operatorname{Tr} A$ while keeping the external and internal abdominal oblique muscles, less contracted. The PAR formula, on the other hand, is calculated by measuring both thicknesses of $\operatorname{Tr} A$ and the lateral abdominal wall muscles (Mangum et al., 2016; Mannion et al., 2008, Teyhen et al., 2005). This calculation helps to measure the patient's ability to isolate spinal stabilizers such as TrA. Although PAR takes into account the entire lateral abdominal wall, AR seems to have higher reliability compared to PAR (Mangum et al., 2016). In this study, we found significant differences in $A R$ and PAR of TrA during drawing-in maneuver between training positions, it was also the case for PAR of $\operatorname{Tr} A$ in Bracing in maneuver but the difference between positions was not significant in case of measuring TrA activation through AR during bracing. A possible explanation for these results might be that PAR measures $\operatorname{Tr} A$ activity isolated from other abdominal wall muscles but $\mathrm{AR}$ is a measure of activation for $\operatorname{Tr} A$ alone.

$\mathrm{AD}$ targets $\operatorname{Tr} \mathrm{A}$ and therefore spinal stability. However, there is some evidence suggesting that bracing exercises can improve both $\operatorname{Tr} A$ activity and spinal stability to a better degree (Grenier and McGill, 2007; Hirayama et al., 2017; Vera-Garcia et al., 2007). Comparing the effect of these two maneuvers it was shown that $\mathrm{AB}$ can produce better motion control and spinal stability against sudden trunk perturbations (Vera-Garcia et al., 2007). In another study by Grenier and McGill both simulation and in vivo findings show that bracing is superior to $\mathrm{AD}$ producing stability (Grenier and McGill, 2007). These findings are also supported by biomechanical studies on the quantification of spinal stability (Grenier and McGill, 2007; Kavcic et al., 2004; McGill et al., 2003). Based on these studies, all trunk muscles must work together to reach spinal stability and stabilization exercises, like $A B$, should focus on the global coactivation of abdominal muscles to reach this goal. Our study and studies showing the superiority of $A B$ in reaching spinal stability do not diminish the significance of $\mathrm{AD}$ maneuver. Rather our findings suggest that the bracing exercises can result in greater $\operatorname{Tr} \mathrm{A}$ activation than $\mathrm{AD}$. The role of $\mathrm{AD}$ could be important in late-stage rehabilitation or maintaining spinal stability in higher demand tasks such as sports training (Monfort-Pañego et al., 2009). Previous studies have also shown that $\operatorname{Tr} A$ might have delayed activity in patients suffering from low back pain which can be treated by drawing-in maneuver (Heidari et al., 2015; Hodges and Richardson, 1998). This might suggest that $\mathrm{AB}$ could be more stabilizing in healthy subjects whereas $\mathrm{AD}$ is more useful in patients with spinal instability or altered muscle functions.

Our study has several limitations. In this study, we did not calculate the reliability of US but it has been extensively tested and shown to be a reliable tool in measuring TrA thickness (Heidari et al., 2015). The PAR formula that we used in this study may increase the sources of error by taking lateral abdominal wall muscles into account. The error might be more significant particularly in more challenging positions. So, the PAR should be interpreted alongside the more reliable AR formula. In our study most of the subjects were female. It has been previously shown that men tend to have greater $\operatorname{Tr} A$ thickness than women (Rho et al., 2013; Springer et al., 2006). Women might also have greater thickness percent change of TrA while performing AD (Rho et al., 2013).

There are many proposed core stability exercises in a variety of positions; however, it is not clear that in which position, activation of transverse abdominis muscle is utmost. We compared the effectiveness of drawing-in and bracing maneuvers in different core stability exercise positions (supine, hook lying, supine with $90^{\circ}$ 
flexed knee and hip, supine with stretched knees and $90^{\circ}$ flexed hips, bridge, bridge with one stretched knee, and Bird dog) through US imaging. We used transverse abdominis $A R$ as a measure of activation and PAR as a measure of the subject's ability to isolate the muscle. Our study showed significantly higher activation of transverse abdominis in bridge position and during $\mathrm{AB}$.

\section{CONFLICT OF INTEREST}

No potential conflict of interest relevant to this article was reported.

\section{ACKNOWLEDGMENTS}

We should thank Mr. Rousta and Mr. Arabi for their kind helps.

\section{REFERENCES}

Djordjevic O, Djordjevic A, Konstantinovic L. Interrater and intrarater reliability of transverse abdominal and lumbar multifidus muscle thickness in subjects with and without low back pain. J Orthop Sports Phys Ther 2014;44:979-988.

Ehsani F, Arab AM, Jaberzadeh S, Salavati M. Ultrasound measurement of deep and superficial abdominal muscles thickness during standing postural tasks in participants with and without chronic low back pain. Man Ther 2016;23:98-105.

Ekstrom RA, Donatelli RA, Carp KC. Electromyographic analysis of core trunk, hip, and thigh muscles during 9 rehabilitation exercises. J Orthop Sports Phys Ther 2007;37:754-762.

Ferreira PH, Ferreira ML, Hodges PW. Changes in recruitment of the abdominal muscles in people with low back pain: ultrasound measurement of muscle activity. Spine (Phila Pa 1976) 2004;29:2560-2566.

Grenier SG, McGill SM. Quantification of lumbar stability by using 2 different abdominal activation strategies. Arch Phys Med Rehabil 2007; 88:54-62.

Heidari P, Farahbakhsh F, Rostami M, Noormohammadpour P, Kordi R. The role of ultrasound in diagnosis of the causes of low back pain: a review of the literature. Asian J Sports Med 2015;6:e23803.

Hirayama K, Akagi R, Moniwa Y, Okada J, Takahashi H. Transversus abdominis elasticity during various exercises: a shear wave ultrasound elastography study. Int J Sports Phys Ther 2017;12:601-606.

Hodges PW. Is there a role for transversus abdominis in lumbo-pelvic stability? Man Ther 1999;4:74-86.

Hodges PW, Moseley GL. Pain and motor control of the lumbopelvic region: effect and possible mechanisms. J Electromyogr Kinesiol 2003;13:
361-370.

Hodges PW, Richardson CA. Delayed postural contraction of transversus abdominis in low back pain associated with movement of the lower limb. J Spinal Disord 1998;11:46-56.

Hwangbo G, Lee CW, Kim SG, Kim HS. The effects of trunk stability exercise and a combined exercise program on pain, flexibility, and static balance in chronic low back pain patients. J Phys Ther Sci 2015;27: 1153-1155.

Kavcic N, Grenier S, McGill SM. Determining the stabilizing role of individual torso muscles during rehabilitation exercises. Spine (Phila Pa 1976) 2004;29:1254-1265.

Kim BJ, Lee SK. Effects of three spinal stabilization techniques on activation and thickness of abdominal muscle. J Exerc Rehabil 2017;13:206209.

Kim M, Kim Y, Oh S, Suh D, Eun SD, Yoon B. Abdominal hollowing and bracing strategies increase joint stability in the trunk region during sudden support surface translation but not in the lower extremities. J Back Musculoskelet Rehabil 2016;29:317-325.

Koh HW, Cho SH, Kim CY. Comparison of the effects of hollowing and bracing exercises on cross-sectional areas of abdominal muscles in middle-aged women. J Phys Ther Sci 2014;26:295-299.

Kordi R, Rostami M, Noormohammadpour P, Mansournia MA. The effect of food consumption on the thickness of abdominal muscles, employing ultrasound measurements. Eur Spine J 2011;20:1312-1317.

Maeo S, Takahashi T, Takai Y, Kanehisa H. Trunk muscle activities during abdominal bracing: comparison among muscles and exercises. J Sports Sci Med 2013;12:467-474.

Mangum LC, Sutherlin MA, Saliba SA, Hart JM. Reliability of ultrasound imaging measures of transverse abdominis and lumbar multifidus in various positions. PM R 2016;8:340-347.

Mannion AF, Pulkovski N, Gubler D, Gorelick M, O'Riordan D, Loupas T, Schenk P, Gerber H, Sprott H. Muscle thickness changes during abdominal hollowing: an assessment of between-day measurement error in controls and patients with chronic low back pain. Eur Spine J 2008;17:494-501.

McGill SM, Grenier S, Kavcic N, Cholewicki J. Coordination of muscle activity to assure stability of the lumbar spine. J Electromyogr Kinesiol 2003;13:353-359.

McMeeken JM, Beith ID, Newham DJ, Milligan P, Critchley DJ. The relationship between EMG and change in thickness of transversus abdominis. Clin Biomech (Bristol, Avon) 2004;19:337-342.

McPherson SL, Watson T. Reproducibility of ultrasound measurement of transversus abdominis during loaded, functional tasks in asymptomatic young adults. PM R 2012;4:402-412.

Mishra P, Pandey CM, Singh U, Gupta A, Sahu C, Keshri A. Descriptive 
statistics and normality tests for statistical data. Ann Card Anaesth 2019;22:67-72.

Monfort-Pañego M, Vera-García FJ, Sánchez-Zuriaga D, Sarti-Martínez MA. Electromyographic studies in abdominal exercises: a literature synthesis. J Manipulative Physiol Ther 2009;32:232-244.

Noormohammadpour P, Ansari M, Mansournia MA, Rostami M, Nourian R, Kordi R. Reversal time of postprandial changes of the thickness of abdominal muscles employing ultrasound measurements. Man Ther 2015;20:194-199.

Noormohammadpour P, Kordi R, Dehghani S, Rostami M. The effect of abdominal resistance training and energy restricted diet on lateral abdominal muscles thickness of overweight and obese women. J Bodyw Mov Ther 2012;16:344-350.

Noormohammadpour P, Kordi M, Mansournia MA, Akbari-Fakhrabadi $\mathrm{M}$, Kordi R. The role of a multi-step core stability exercise program in the treatment of nurses with chronic low back pain: a single-blinded randomized controlled trial. Asian Spine J 2018;12:490-502.

Norris CM. Abdominal muscle training in sport. Br J Sports Med 1993; 27:19-27.

Panjabi MM. The stabilizing system of the spine. Part I. Function, dysfunction, adaptation, and enhancement. J Spinal Disord 1992;5:383-389.

Rho M, Spitznagle T, Van Dillen L, Maheswari V, Oza S, Prather H. Gender differences on ultrasound imaging of lateral abdominal muscle thickness in asymptomatic adults: a pilot study. PM R 2013;5:374-380.

Rostami M, Ansari M, Noormohammadpour P, Mansournia MA, Kordi R. Ultrasound assessment of trunk muscles and back flexibility, strength and endurance in off-road cyclists with and without low back pain. J Back Musculoskelet Rehabil 2015;28:635-644.

Selkow NM, Eck MR, Rivas S. Transversus abdominis activation and timing improves following core stability training: a randomized trial. Int J Sports Phys Ther 2017;12:1048-1056.

Springer BA, Mielcarek BJ, Nesfield TK, Teyhen DS. Relationships among lateral abdominal muscles, gender, body mass index, and hand dominance. J Orthop Sports Phys Ther 2006;36:289-297.

Teyhen DS, Miltenberger CE, Deiters HM, Del Toro YM, Pulliam JN, Childs JD, Boyles RE, Flynn TW. The use of ultrasound imaging of the abdominal drawing-in maneuver in subjects with low back pain. J Orthop Sports Phys Ther 2005;35:346-355.

Vera-Garcia FJ, Elvira JL, Brown SH, McGill SM. Effects of abdominal stabilization maneuvers on the control of spine motion and stability against sudden trunk perturbations. J Electromyogr Kinesiol 2007;17:556-567.

Willson JD, Dougherty CP, Ireland ML, Davis IM. Core stability and its relationship to lower extremity function and injury. J Am Acad Orthop Surg 2005;13:316-325.

Woolf AD, Pfleger B. Burden of major musculoskeletal conditions. Bull World Health Organ 2003;81:646-656. 